\title{
Nutritional Status of Rural Bengali Adolescent Boys of Tripura
}

\author{
Sandeep Roy Sarkar ${ }^{1} \cdot$ Samir Kumar Sil ${ }^{1}$
}

Received: 11 April 2015 / Accepted: 16 July 2015 /Published online: 20 August 2015

(C) Dr. K C Chaudhuri Foundation 2015

To the Editor: Assessment of nutritional status is significant in developing countries like India where the vast majority of the populations are undernourished and underprivileged. Studies describing the nutritional status of adolescents from northeastern part of India are limited. This community based cross-sectional study was conducted to determine the current nutritional status of rural adolescent Bengali boys of Tripura.

A total of 550 school-going Bengali boys (aged 8-16 y) from 30 randomly selected villages, representing the state of Tripura, were included using multistage cluster sampling method. Standing height and body weight were measured; body mass index (BMI) was derived. Age specific prevalences of stunting, thinness, overweight and obesity were calculated according to the classification of World Health Organization (WHO) [1], using the new IAP growth charts [2]. Nutritional status was also assessed using the $2007 \mathrm{WHO}$ growth reference data [3].

These boys had lower socio-economic status. Using the IAP growth charts [2] as reference, the overall (age combined) prevalence of stunting (height-for-age $<3$ rd percentile) was found low: $9.09 \%$. Prevalence across age groups fluctuated from 0 to $21.31 \%$ below the 3 rd percentile. The overall prevalence of thinness (i.e., BMI-for-age $<5$ th percentile) was $12 \%$, which is higher than that of stunting. Prevalence across age groups fluctuated from 6.45 to $16.67 \%$ below the 5 th percentile. The overall prevalence of overweight (i.e., BMIfor-age $\geq 23$ adult equivalent) was $7.09 \%$. Prevalence across age groups fluctuated from 1.67 to $11.29 \%$. The overall age specific prevalence of obesity (i.e., BMI-for-age $\geq 27$ adult equivalent) was very low $(0.36 \%)$. The overall prevalence

Sandeep Roy Sarkar

sndprysrkr@rediffmail.com

1 Department of Human Physiology, Tripura University, Suryamaninagar 799022, Tripura, India of stunting and thinness ( 21.15 and $40.32 \%$ respectively) was found higher and overweight (4.30\%) was found lower when WHO reference data [3] was used. The prevalence rate of undernutrition among the boys of the present study was comparatively lower than the urban Bengali boys of Kolkata [4] and rural tribal children of Tripura [5].

In general, the Bengali boys of Tripura had lower rates of undernutrition. The over diagnosis of undernutrition and under diagnosis of overnutrition may be avoided by using the new IAP growth charts. We propose that future studies should use these charts to determine the growth and nutritional status of children and adolescents from India.

Acknowledgement The authors thank Prof. Parasmani Dasgupta, Biological Anthropological Unit, Indian Statistical Institute, Kolkata for his guidance. Also, they thank participating students and school authorities for their cooperation.

Conflict of Interest None.

Source of Funding The research is funded by Tripura University in the form of RET fellowship to the first author.

\section{References}

1. WHO Physical Status: The use and interpretation of anthropometry. Report of a WHO Expert Committee. Geneva: World Health Organization, Technical Report Series no. 854., 1995; 1-452.

2. Indian Academy of Pediatrics Growth Charts Committee, Khadilkar V, Yadav S, Agrawal KK, et al. Revised IAP growth charts for height, weight and body mass index for 5- to 18-year-old Indian children. Indian Pediatr. 2015; 52: 47-55.

3. World Health Organization. Growth Reference Data for 5-19 years. 2007. Available at: www.who.int/growthref/who2007/en/index. html. Assessed on 10 Sept 2014.

4. de Onis M, Dasgupta P, Saha S, Sengupta D, Blossner M. The National Center for Health Statistics reference and the growth of Indian adolescent boys. Am J Clin Nutr. 2001;74:248-53.

5. Sil SK, Sarkar SR, Saha S, Roy S. Assessment of nutritional status of rural tribal children in Tripura. Indian Pediatr. 2011;48:488-9. 